\title{
Studies on Apple Canker Disease. The Necrotic Toxins Produced by Valsa ceratosperma ${ }^{\dagger}$
}

\author{
Hidehiko Natsume, Haruo Seto and Noboru ŌTake \\ Institute of Applied Microbiology, The University of Tokyo, \\ Bunkyo-ku, Tokyo 113, Japan
}

Received February 16, 1982

\begin{abstract}
Several metabolites responsible for the toxic manifestations of Valsa ceratosperma (Toda et Fries) Maire, a phytopathogenic fungus of the Japanese apple canker, have been isolated from its culture filtrate after growth on apple branch extract. Chemical and spectrometric studies revealed the products to be degradation products of phlorizin which is a dominant component distributed in leaves, stems, fruits and roots of apple. The toxic substances were identified as 3-( $p$-hydroxyphenyl) propionic acid, phloroglucinol, $p$-hydroxyacetophenone, $p$-hydroxybenzoic acid and protocatechuic acid. All of these compounds except $p$-hydroxyacetophenone were detected in the lesions of apple trees infected by $V$. ceratosperma. The fungus cultivated in a medium containing added phlorizin also produced the five toxic substances mentioned above. These results suggest that phlorizin is involved in the specific relationship between the host and the pathogen, indicating that the degradation products of phlorizin play important roles in the production of symptoms of infected apple trees.
\end{abstract}

Apple canker disease is now epidemic in many areas in Japan, and is a serious economic problem in apple production. The symptoms of several plant diseases are known to be caused by host-specific toxins produced by the pathogenic fungi. The characteristic symptom observed of apple trees infected by $V$. ceratosperma is necrosis of branches and trunks.

In spite of intensive investigations, ${ }^{1)}$ the primary cause of necrosis due to the fungus remained to be clarified. Now we have succeeded in isolating and identifying the toxic substances produced by $V$. ceratosperma, and in revealing the mechanism of the necrosis caused by the pathogen.

In our experiments, toxic substances present in spreading lesions were investigated from the viewpoint of phytopathology, with the main interest being in the specific relationship between the host and the pathogen, $V$. ceratosperma.

The results indicated that the apple canker was a host-dependent disease whose cause has been elucidated for the first time.

\section{MATERIALS AND METHODS}

Bioassay. At the beginning of the isolation process, we used a cut branch method as well as a lettuce germination test for bioassaying of toxic substances. After confirmation of the difference between the two methods for evaluating the toxicity, the latter was used for toxic materials, since the former was too timeconsuming. The cut branch method was utillized again in the final purification stage to confirm the activities of the isolated toxins.

Cut branch method. Absorbent cotton impregnated with $2.5 \mathrm{ml}$ of an aqueous solution of a test sample was placed on the top cut end of a one or two year old apple branch which was about $1 \mathrm{~cm}$ in diameter and $15 \mathrm{~cm}$ in length. The cotton was covered with a piece of aluminum foil to prevent evaporation of water from the top end. After 3, 5, 7 and 14 days at $20^{\circ} \mathrm{C}$, symptoms of necrosis were carefully examined.

Lettuce germination test. Seeds of lettuce (Great Lakes 366) were placed on filter paper impregnated with a sample solution in a Petri dish and $0.4 \mathrm{ml}$ of water was added. The dish was incubated in the dark at $20^{\circ} \mathrm{C}$. Inhibition of seed

${ }^{\dagger}$ This paper was presented at the Annual Meeting of the Agricultural Chemical Society of Japan, Kyoto, March 31,1981 . 
germination was examined after two days.

Culture media. Of the several media tested, the apple branch extract medium was the only satisfactory one for the toxin production by $V$. ceratosperma. The medium consists of apple branch extract, prepared by boiling $150 \mathrm{~g}$ of branch in $500 \mathrm{ml}$ of water for $30 \mathrm{~min}, 0.2 \%$ yeast extract powder and $4 \%$ sucrose. The $\mathrm{pH}$ was adjusted to 5.8

TABle I. Yield of Toxins IN VARIOUS KINDS OF MEDIA

\begin{tabular}{lcc}
\hline Medium & $\begin{array}{c}\text { Submerged } \\
\text { culture }\end{array}$ & $\begin{array}{c}\text { Stationary } \\
\text { culture }\end{array}$ \\
\hline $\begin{array}{l}\text { Glucose-Czapek } \\
+ \text { yeast extract }\end{array}$ & - & - \\
$\begin{array}{l}\text { Raulin-Thom } \\
+ \text { yeast extract }\end{array}$ & - & - \\
$\begin{array}{l}\text { Richards } \\
+ \text { yeast extract }\end{array}$ & - & - \\
Yeast-sucrose & - & - \\
Potato-sucrose & - & - \\
Prune-sucrose & - & ++ \\
Apple branch & - & \\
extract & ++ & \\
\hline
\end{tabular}

before sterilization. $V$. ceratosperma was submergecultured and the toxin titres obtained within a few days were almost equivalent to those produced under stationary cultural conditions for $3 \sim 4$ weeks. Therefore, the submerged culture was adopted throughout this experiment. The yields of toxins in various kinds of media are summarized in Table I.

Isolation of toxins. V. ceratosperma was maintained on apple branch extract agar slants containing $4 \%$ agar. After incubation at $27^{\circ} \mathrm{C}$ for 21 days, sterilized water $(2 \mathrm{ml})$ was added to each slant and the fungus was scraped out to prepare a spore suspension.

Two $\mathrm{ml}$ of this inoculum was added to $200 \mathrm{ml}$ of the apple branch extract medium in $500 \mathrm{ml}$ Erlenmeyer flasks, and cultivation was conducted at $27^{\circ} \mathrm{C}$ for 6 days on a reciprocal shaker.

The isolation procedures for the toxins are summarized in Chart 1.

The broth filtrate (6 liters, $\mathrm{pH} 4$ ) was adjusted to $\mathrm{pH} 3$ with $1 \mathrm{~N} \mathrm{HCl}$ solution and extracted with ethyl acetate. The organic phase was concentrated in vacuo to remove the solvent. Then, the extract was purified by silica gel column chromatography using a solvent system of chloroform-methanol $(5: 1)$ to give three toxic fractions. Further purification of these fractions was achieved separately by common procedures, i.e. column chromatography on Sephadex LH-20 (solvent: methanol) and on silica gel (solvent system: chloroform-methanol $=50: 1$ ).

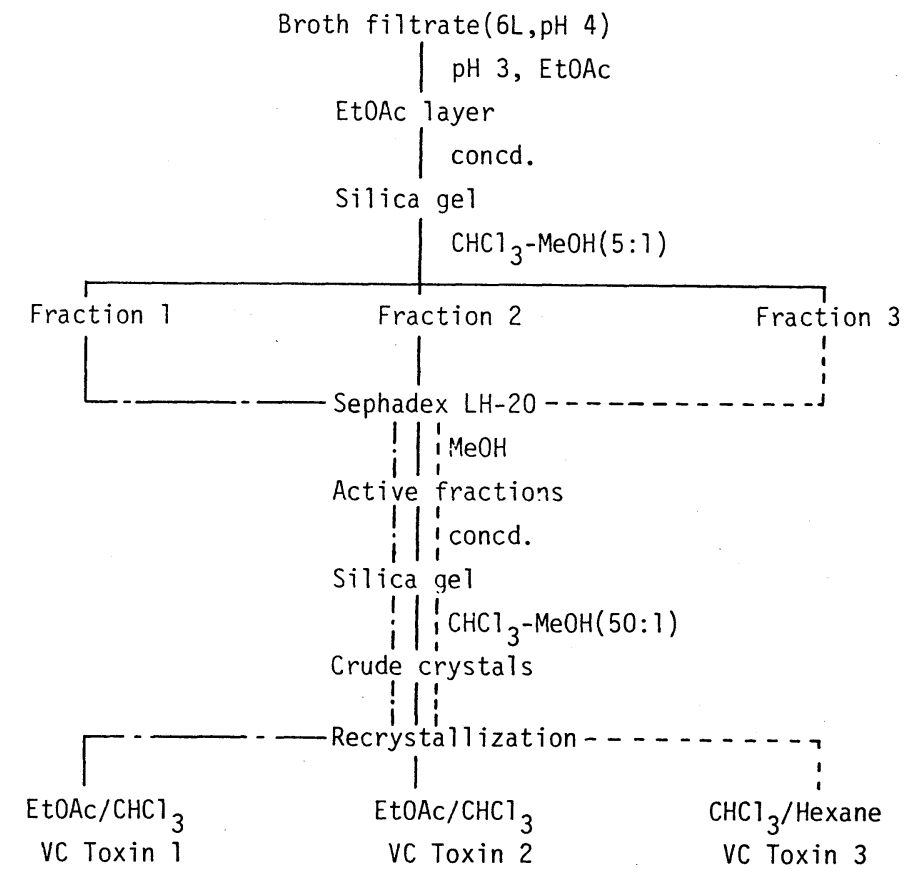

CHART 1. Isolation and Purification Procedures for VC Toxins 1, 2 and 3. 


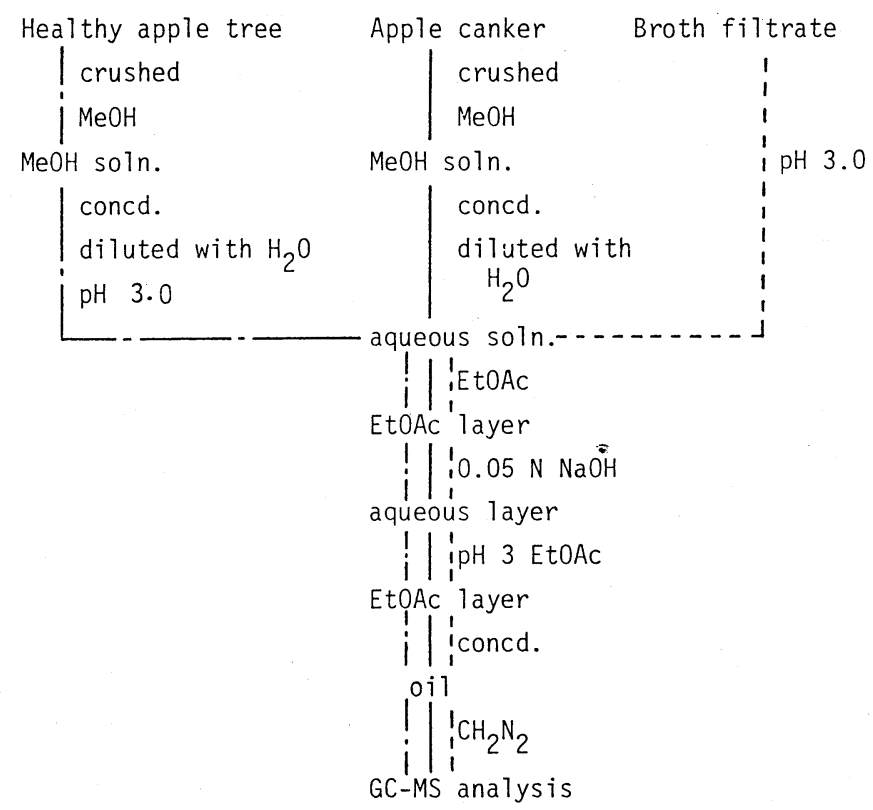

Chart 2. The Procedures for Detection of Toxic Substances.

The purified toxic fractions were evaporated in vacuo to give crude crystals. Recrystallization from ethyl acetatechloroform or chloroform-hexane gave colorless needles of VC toxins 1, 2 and 3.

Since the toxins were produced only in the medium supplemented with apple extract, it was necessary to clarify whether they are inherent constituents of apple plants or metabolites produced by $V$. ceratosperma. To this end, healthy apple branches $(120 \mathrm{~g})$ and diseased ones $(120 \mathrm{~g})$ infected by the pathogen were extracted separately with methanol, and the extracts were subjected to GC-MS $\left(1.5 \% \mathrm{OV}-1,3 \mathrm{~mm} \times 200 \mathrm{~cm}, 140^{\circ} \mathrm{C}\right)$ analysis. In addition, metabolites of the fungus produced under submerged conditions were also investigated by GC-MS analysis of the ethyl acetate extract of the fermentation broth. The procedures for detection of toxic substances are summarized in Chart 2. Branches or trunks of infected apple trees were crushed into small pieces and extracted with methanol. The solution was concentrated in vacuo to a small volume, and the residue, after dilution with water, was extracted with ethyl acetate. The toxic compounds were then transferred to a $0.05 \mathrm{~N} \mathrm{NaOH}$ solution, and reextracted with ethyl acetate at $\mathrm{pH} 3$. The extract, which was methylated with diazomethane, was subjected to GCMS analysis. The same procedures were applied to healthy apple plants. The analysis of broth filtrate was carried out as described previously.

\section{RESULTS}

The isolated metabolites, named VC toxins
1, 2 and 3, were identified as 3-( $p$-hydroxyphenyl) propionic acid, phloroglucinol and $p$ hydroxyacetophenone, respectively, on the basis of NMR (JEOL, JNM-FX-400 (400 $\mathrm{MHz})$ ), mass and IR spectral data and their physicochemical properties as summarized in Table II. Their structures were further supported by comparison with authentic samples. The following amounts of VC toxins 1, 2 and 3 were obtained from 6 liters of cultured broth; $\mathrm{VC}$ toxin $1(946 \mathrm{mg}), \mathrm{VC}$ toxin $2(805 \mathrm{mg})$ and $\mathrm{VC}$ toxin $3(67 \mathrm{mg})$. In addition to these compounds, GC-MS analysis revealed the presence of two new toxic substances, i.e. $p$-hydroxybenzoic acid (VC toxin 4; $206 \mathrm{mg}$ ) and protocatechuic acid (VC toxin 5; $722 \mathrm{mg}$ ) in the broth filtrate. The structures of these two metabolites were confirmed by direct comparison with authentic specimens. In affected apple plants, four toxic substances, $\mathrm{VC}$ toxins 1 (400 mg), 2 and 4 (614 mg), and 5 (175 mg) had been detected before. On the other hand, VC toxin $1(2 \mathrm{mg})$ was detected in healthy apple, but the amount was very small. The structures of these compounds indicated that VC toxins $1 \sim 5$ were the degradation products of phlorizin ${ }^{2 \sim 8)}$ which is abundantly distrib- 
Table II. Physicochemical Properties of Toxins 1, 2 and 3

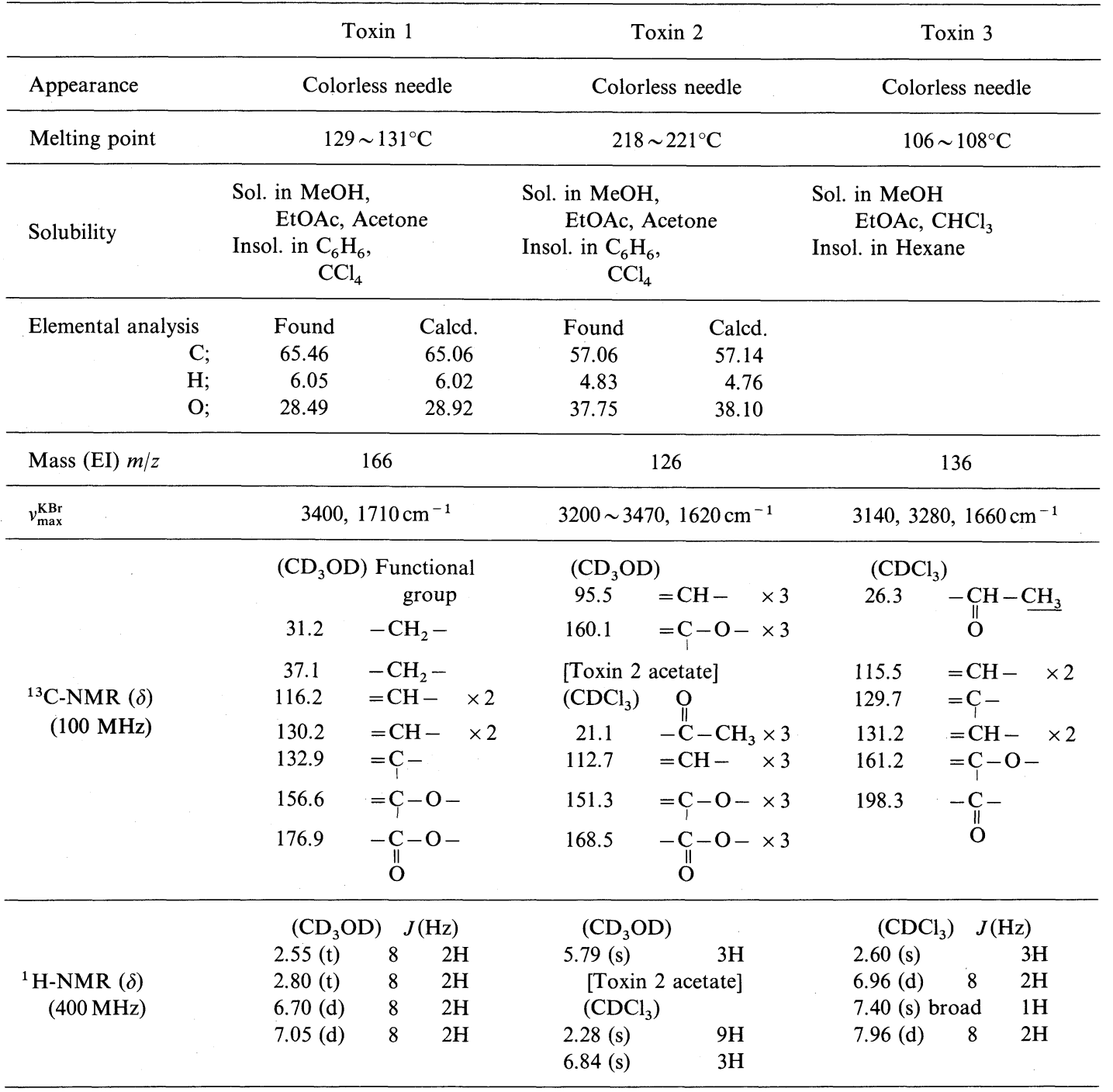

uted in leaves, stems, fruits and roots of apple trees.

In order to elucidate the role of the parasite in relation to the metabolism of phlorizin, $V$. ceratosperma was cultivated in modified glucose-Czepek medium $(500 \mathrm{ml})$ containing $0.2 \%$ yeast extract powder supplemented with phlorizin $(0.5 \mathrm{mg} / \mathrm{ml} \mathrm{medium})$ for 4 days at $27^{\circ} \mathrm{C}$ on a reciprocal shaker. The broth filtrate was subjected to GC-MS analysis. VC-toxin 1 $(3.3 \mathrm{mg}), 2$ and $4(50 \mathrm{mg}), 3(16.7 \mathrm{mg})$ and 5 $(30 \mathrm{mg})$ were detected in the broth filtrate to
Table III. Minimum Browning Concentration

1. 3-( $p$-Hydroxyphenyl)propionic acid

$0.95 \mathrm{mg} / \mathrm{ml}$

2. Phloroglucinol $3.00 \mathrm{mg} / \mathrm{ml}$

3. $p$-Hydroxyacetophenone

4. $p$-Hydroxybenzoic acid $0.95 \mathrm{mg} / \mathrm{ml}$ $2.50 \mathrm{mg} / \mathrm{ml}$ $1.25 \mathrm{mg} / \mathrm{ml}$

which phlorizin had been added. It is quite obvious, therefore, that these detected substances are fungal metabolites of phlorizin. The minimum browning concentrations of VC toxins $1 \sim 5$ are summarized in Table III. 


\section{DISCUSSION}

It is well known that phlorizin is widely distributed in each tissue of the apple tree. Our experiments indicated that $V$. ceratosperma can metabolize phlorizin, a trypical constituent of the genus Malus, into five toxic substances, 3-( $p$-hydroxyphenyl) propionic acid, phloroglucinol, $p$-hydroxyacetophenone, $p$-hydroxybenzoic acid and protocatechuic acid.

Williams et al..$^{9 \sim 11)}$ proposed a hypothetical metabolic scheme for degradation of phlorizin by Venturia inaequalis in 1961. The enzymatic degradation of phlorizin was assumed to be as in the works of Börner, ${ }^{2)}$ Sleeper and Stanier ${ }^{12}$ )

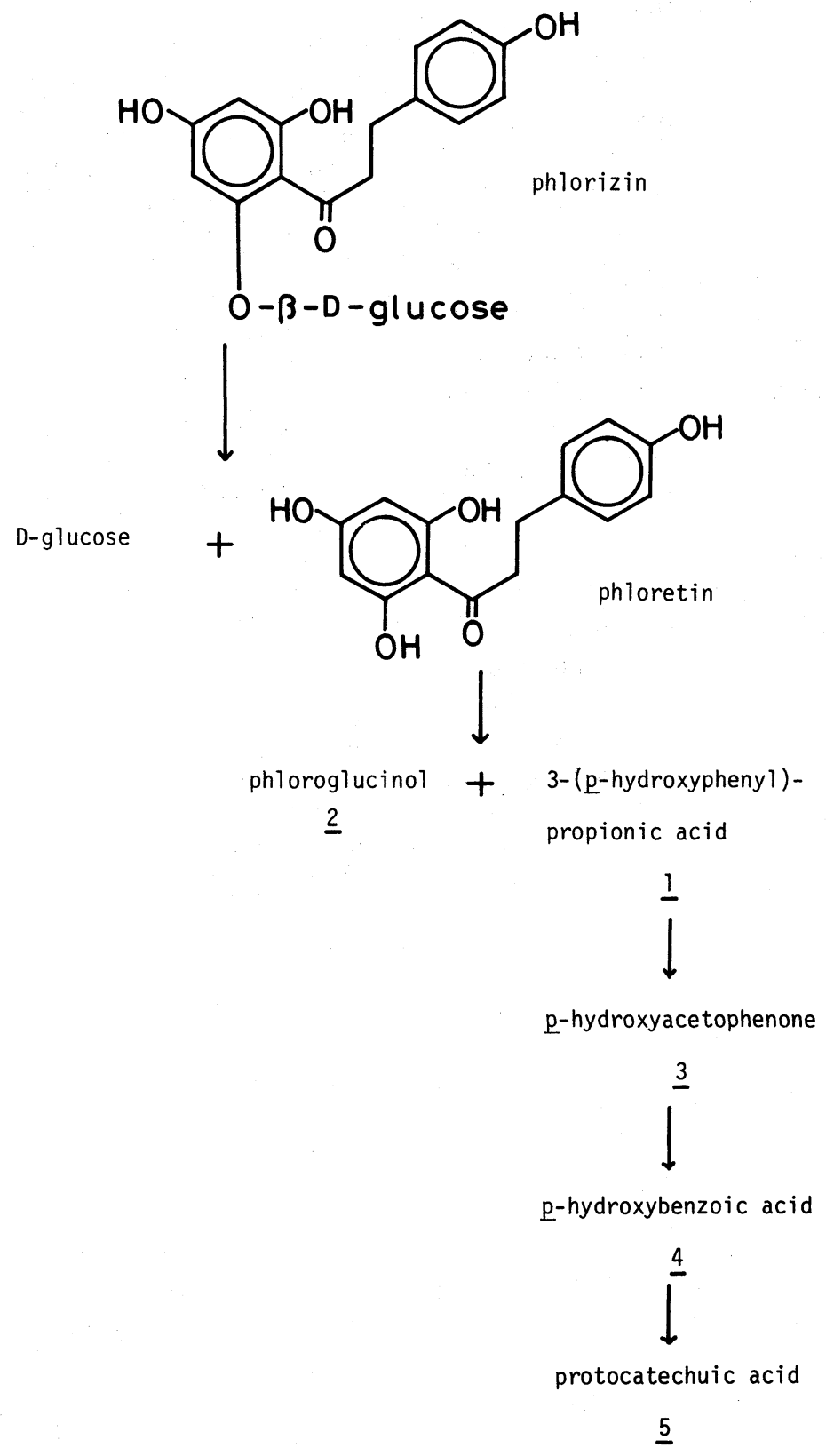

Chart 3. 
and Stanier et al. ${ }^{13)}$ On the basis of our experimental data and the scheme of Williams et al., we propose the scheme summarized in Chart 3 for degradation of phlorizin by $V$. ceratosperma in the apple plant.

It is clear that phlorizin and its degradation products play an important role in the hostparasite interactions in the Japanese apple canker for the following reasons; (1) phlorizin exists in a high concentration in the host plant, (2) its distribution is characteristic of the genus Malus, (3) the parasite can metabolize phlorizin, and (4) the degradation products of phlorizin produce a symptom similar to that of bark infected with the pathogen. Therefore, it may be concluded that the symptom of apple canker, i.e. necrosis, is caused by the action of $V$. ceratosperma on the constituents of the apple plant. In this context, apple canker can be regarded as a kind of host-dependent disease.

During this work, we noticed that the sporulation and growth of the fungus were much better in apple branch extract medium than in other natural or artificial media. Similar results were not obtained in other culture media supplemented with phlorizin only. Therefore, constituents of apple plants other than phlorizin may also play some roles in the apple canker disease. Studies to clarify this problem are now under way.
Acknowledgments. The authors are indebted to Dr. A. Yamaguchi, Okitsu Brand Fruit Tree Research Station, and Dr. T. Sakuma and Dr. H. Koganezawa, Morioka Branch Fruit Research Station, Ministry of Agriculture, Forestry and Fisheries for their kind suggestions and advice on the apple canker disease.

This work was supported by a Grant-in-Aid for Special Project Research (56112007) from the Ministry of Education, Science and Culture of Japan.

\section{REFERENCES}

1) T. Okuno, S. Oikawa, T. Goto, M. Toda, K. Sawai, K. Sawamura and T. Matsumoto, Abstract of the 23rd Symposium on the Chemistry of Natural Products, Nagoya, October, 1980, p. 530.

2) H. Börner, "The Apple Replant Problem," I. The Excretion of Phlorizin from Apple Root Residues, Vol. 20, Contrib. of Boyre Thompson Inst., 1959, p. 39.

3) L. Califano, Biochem. S., 271, 123 (1934).

4) J. S. Challice, Phytochemistry, 12, 1095 (1973).

5) A. Hutchinson, C. Roy and G. H. N. Towers, Nature, 181, 841 (1958).)

6) A. Hutchinson, C. D. Taper and G. H. N. Towers, Can. J. Biochem. Physiol., 37, 901 (1959).

7) D. V. Richmond and J. T. Martin, Ann. Appl. Biol., 47, 583 (1959).

8) H. D. Wright, J. Pathol. Bacteriol., 45, 117 (1937).

9) E. B. Williams and E. H. Barnes, Can. J. Microbiol., 7, 525 (1961).

10) E. B. Williams, J. Holowczak and J. Kuc, Phytopathology, 52, 1019 (1962).

11) E. B. Williams, J. Wallace and J. Kuc, Phytopathology, 52, 1004 (1962).

12) B. P. Sleeper and R. Y. Stanier, J. Bacteriol., 59, 117 (1950).

13) B. P. Sleeper, R. Y. Stanier, M. Tsuchida and D. L. MacDonald, J. Bacterial., 59, 137 (1950). 